\title{
Imaging Appearances in a Case of Tumoral Calcinosis
}

\section{SUSHIL G. KACHEWAR, DEVIDAS S. KULKARNI}

\section{ABSTRACT}

Tumoral calcinosis is an uncommon entity characterised by calcified para-articular masses as demonstrated most often on radiographs. It can occur at any age and is inherited as an autosomal dominant mode that has a variable clinical expression. Its biochemical hallmarks are hyperphosphataemia with normocalcaemia and normal renal function.

It is only rarely that one comes across a disease which is so obvious in its clinical manifestations that it should easily be recognized and yet which is frequently misdiagnosed and dismissed as something else for example "foreign body reactions", "old trauma", "sebaceous cysts with secondary calcification", "periarticular giant cell tumours" and "unknown embryonic tumours" to quote a few examples. As it has a potential to produce tumours weighing as much as $4,000 \mathrm{~g}$, which are often multiple and cause pressure symptoms, which may necrose, recur after removal, cause considerable pain and morbidity and, may even endanger the of the patient, it is entitled to a little more "respect".

Unfamiliarity with tumoral calcinosis as well as the disease processes that mimic this condition; impedes the correct diagnosis thereby delaying the treatment, and an undue alarm could be raised, possibly leading to unwarranted surgical procedures. Hence, we all need to be familiar with this entity.

\section{CASE REPORT}

A 45 years female presented with a painless progressive swelling on the inner aspect of left arm which she had been noticing for the past 6 months. It was the stony hard feeling inside this lump that made her seek medical consultation. On inspection, there was an irregular soft tissue bulge on the inner aspect of left upper arm. The overlying skin was normal and intact. There were no signs of any local inflammation. On palpation a firm multilobulated soft tissue lump was palpable. At places in it, a stony hard feel was present. There was no tenderness. The shoulder movements were not yet restricted.

Plain Radiograph [Table/Fig-1] demonstrated multilobulated radio-dense mass on the medial aspect of left upper arm. Gradient Echo Axial MRI image [Table/Fig-2] showed calcified lesions on medial aspect of left humeral head seen as hypo intensities inside the multilobulated soft tissue mass. Same findings were also appreciated on T1W and Short Tau Inversion Recovery (STIR) MRI sequences in coronal plain [Table/Fig-3]. As the patient was too much concerned about the mass lesion, it was excised and sent for histopathological evaluation that confirmed it as Tumoral calcinosis owing to the presence of calcifications in the soft tissues. Similar multilobulated soft tissue mass was also seen in a 61 years male [Table/Fig-4] in the lower pelvis on a radiograph of pelvis taken as had a complaint of vague discomfort in the lower pelvic region. This too was radiologically labelled as tumoral calcinosis and is under observation as the patient didn't want any surgery.

\section{DISCUSSION}

Numerous masses around the joints not associated with any pain are the hallmarks of tumoral calcinosis. In tumoral calcinosis multiple calcifications are seen distributed along the extensor surfaces of large joints causing lobulated enlargement of soft tissues. The list of differential diagnosis is large. It is vital therefore vital that the imaging specialists aware of this entity so that unnecessary invasive procedures are avoided and appropriate tests are done for confirmation $[1,2]$.

The soft tissue lesions proliferate during the first two decades of life. Commonly affected regions are the hip, elbow, shoulder, foot, and wrist. Intra-op these lesions are cystic and contain 


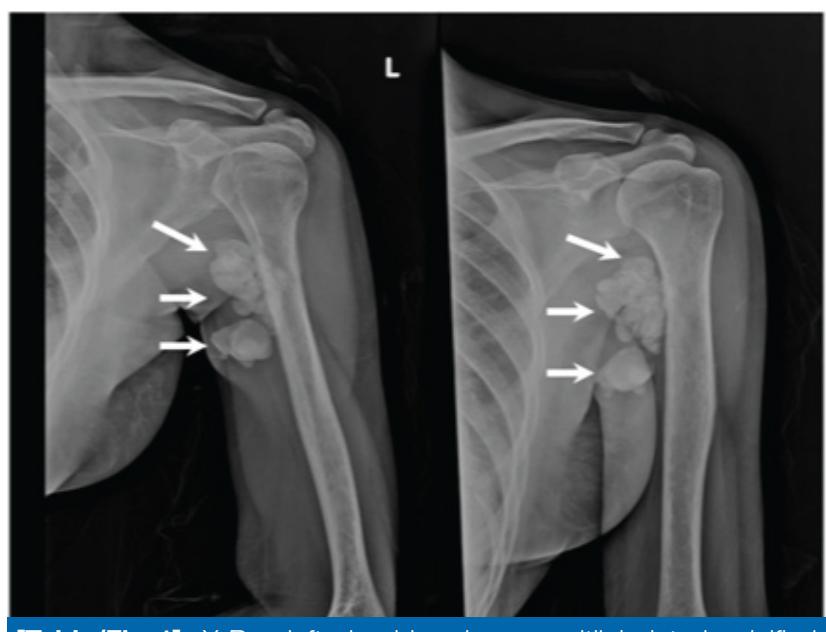

[Table/Fig-1]: X-Ray left shoulder shows multilobulated calcified mass on medial aspect of upper arm.
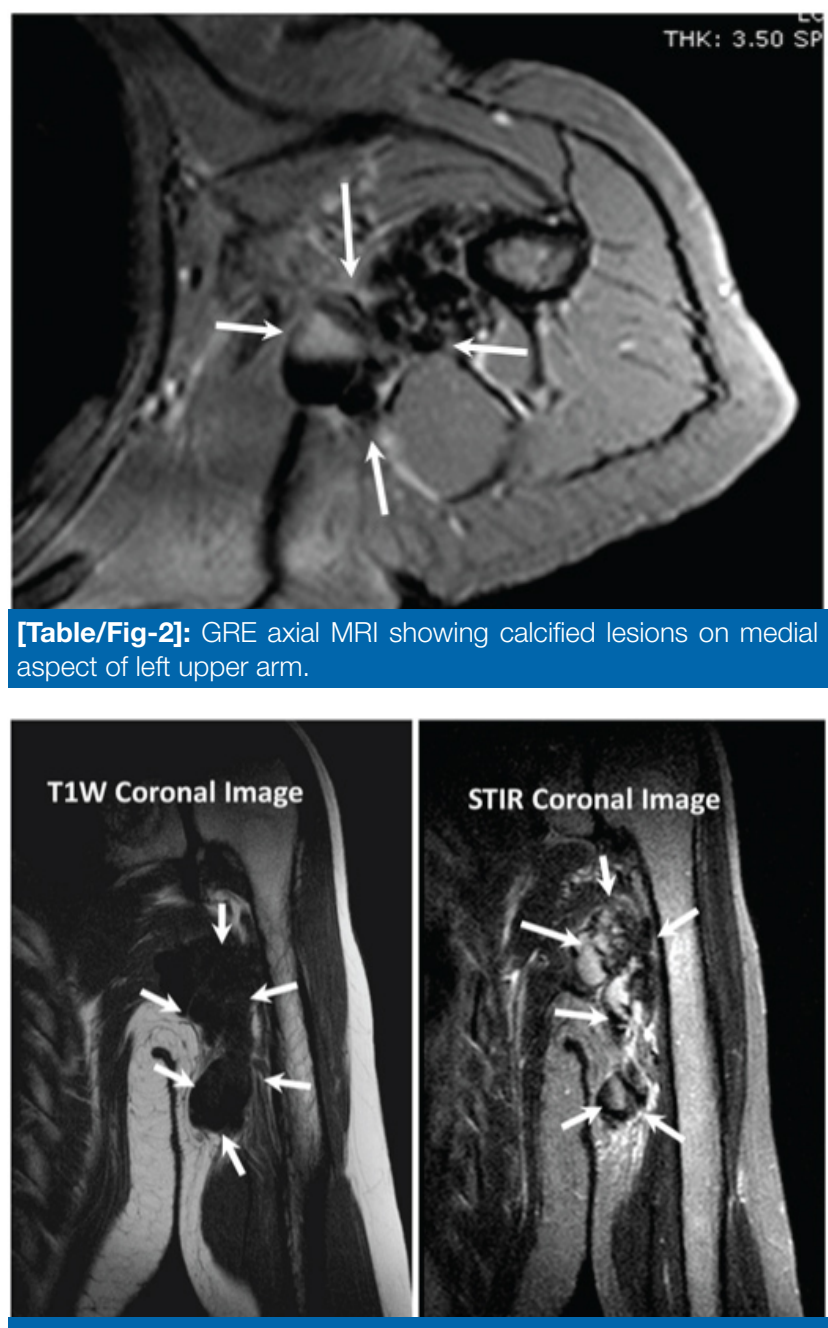

[Table/Fig-3]: T1W and STIR Coronal MRI Images showing calcified lesions on medial aspect of left upper arm.

calcium hydroxyl-apatite crystals with amorphous calcium carbonate and calcium phosphate [3,4].

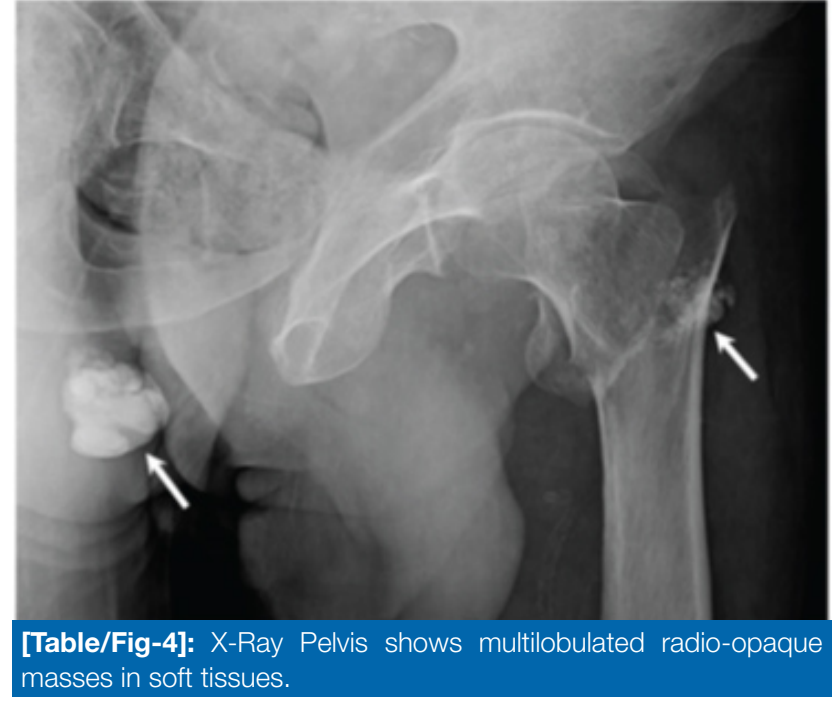

Epithelioid cells and multinucleated giant cells are noted around calcium granules on histopathology.

Patients with this entity may also have problems of teeth $[4,5]$ and disorders of knee as well as temporo mandibular joint. Spine, sacrum, scalp and even hand may be affected [5]. A pathogenesis-based classification was put forth by Smack et al., [6]:

(a) Primarynormophosphataemic tumoral calcinosis,

(b) Primaryhyperphosphatemic tumoral calcinosis, and

(c) Secondary tumoral calcinosis.

Hence, it was necessary that this term "tumoral calcinosis" be strictly used in reference to a disease caused by a hereditary metabolic dysfunctionof phosphate regulation associated with massive periarticular calcinosis.

Clinically the patients complain of swelling and disability when the tumors are large and of pain when there is pressure on a nerve. There is no complaint of pain in the tumor itself. There is no reaction in the overlying skin except where, in primitive people especially, pressure has caused skin changes due to sleeping on hard ground.

Many of the tumors are incidental findings on X-ray examination for other reasons and have been mistaken for bone infarcts, calcified glands, calcified bursa, old injections, mycotic abscesses and such lesions. Quite a few are multiple. The clinical history is unhelpful. The lump grows slowly over some years. There is no polydypsia, polyuria, lethargy, weakness, arthritis or muscle pain, no renal calculi, known trauma or vascular changes. Milk intake is normal and in usually low. No abnormal intake of vitamins or antacids has been found.

Multilobulated amorphous calcifications are classic on radiography. Sedimentation sign is the term coined for fluid- 
fluid leveling seen on CT scan [7]. Adjacent bone destruction is however not caused by this mass. MRI enables multiplanner imaging and on T2 images demonstrates either hypointense areas diffusely or alternating hypo-hyper intense areas in nodular pattern [8]. The calcifications are better seen on Gradient Echo Images. Radionuclide images have been used in diagnosing the para-articular soft tissue masses of tumoral calcinosis. It is the most reliable and simplest method for detection and localization and assessment of the calcific masses. Uptake of the phosphate compounds labelled with 99-Tc-M by the calcific masses is probably related to surface absorption of hydroxyapatite crystal.Imaging differentials include calcifications in chronic renal failure, calcinosis universalis, synovial osteochondromatosis, myositis ossoficans and even Osteosarcoma. But location, imaging appearance and biochemical tests are helpful in reaching the exact diagnosis. Treatment depends on size and location. Surgical excision is practiced with a wide margin, although recurrence.

\section{CONCLUSION}

Tumoral calcinosis is rare entity that has many mimics. Typical imaging appearances as described coupled with findings of hyperphosphataemia with normocalcaemia and normal renal function, can be diagnostic.

\section{REFERENCES}

[1] Inclan A, Leon P, Camejo MG. Tumoral calcinosis. J Am Med Assoc. 1943; 121:490-95.

[2] Fathi I, Sakr M. Review of tumoral calcinosis: A rare clinicopathological entity. World Journal of Clinical Cases. 2014; 2(9):409-14.

[3] Dimitroulis G. Tumoral calcinosis of the articular disc of the temporomandibular joint: a rare entity. J Oral Maxillofac Surg. 2004;62:1551-53.

[4] Xu C, Potter JA, Carter CD, Lang CMC. Idiopathic tumoral calcinosis in hand: a case report. Eplasty. 2014;14:e28.

[5] McGuinness FE. Hyperphosphataemictumoralcalcinosis in bedouin Arabs: clinical and radiological features. Clin Radiol. 1995; 50:259-64.

[6] Smack D, Norton SA, Fitzpatrick SE. Proposal for pathogenesisbased classification of tumoral calcinosis. Int J Dermatol. 1996; 35:265-71.

[7] Hug I, Guncaga J. Tumoral calcinosis with sedimentation sign. Br J Radiol. 1974; 47:734-36.

[8] Martinez S, Vogler JB, Harrelson JM, Lyles KW. Imaging of tumoral calcinosis: new observations. Radiology. 1990; 174:215-22.

\section{AUTHOR(S):}

1. Dr. Sushil G. Kachewar

2. Dr. Devidas S. Kulkarni

\section{PARTICULARS OF CONTRIBUTORS:}

1. Professor, Department of Radio-diagnosis, PDVPFs Medical College, VIMS, Ahmednagar, India.

2. Professor, Department of Radio-diagnosis, Rural Medical College (RMC), PIMS, Loni, India.
NAME, ADDRESS, E-MAIL ID OF THE CORRESPONDING AUTHOR:

Dr. Sushil G. Kachewar,

Professor, Department of Radio-diagnosis, PDWPFs Medical College, VIMS, Ahmednagar-414 111, India.

E-mail: sushilkachewar@hotmail.com

FINANCIAL OR OTHER COMPETING INTERESTS: None. 